\title{
Comparison of forced oscillation technique and spirometry in paediatric asthma
}

\section{To the Editor:}

The Global Initiative for Asthma report emphasises the use of spirometry in diagnosing and monitoring asthma in children from 6 years of age onwards [1]. Spirometry requires good cooperation and younger children are sometimes unable to perform repeated forced expiratory blows [2]. Alternative pulmonary function measurements, such as the forced oscillation technique (FOT), are increasingly available for children at preschool age [3]. FOT measures lung function by imposing small soundwaves over tidal breathing through a mouthpiece, where pressure and flow changes in the airways are measured to derive respiratory system properties $[4,5]$. The first study on bronchodilator responses by FOT in preschool-aged children was published already two decades ago [6]. Guidelines endorse the use of respiratory oscillometry in diagnosing and following up asthma in young children [3,7], and it has shown potential in predicting loss of asthma control in older children and adolescents [8]. However, little is known of how FOT indices correlate with flow-volume indices when this technique is used in adjunct with conventional spirometry.

The children's respiratory assessment laboratory in Evelina London Children's Hospital (London, UK) has been using a commercial FOT application with fixed frequency at $8 \mathrm{~Hz}$ oscillation input. We hypothesised that baseline and post-bronchodilator lung function measurements by FOT would have a mutual relationship with spirometry measurements obtained at the same visit, in children with moderate to severe asthma. In addition, we aimed to investigate agreement between the two methods regarding bronchodilator responsiveness (BDR).

Measurements were collected from a tertiary level asthma clinic between January and June in 2017. The data consisted of 72 sequential clinic visits from an ethnically diverse regional population. First, baseline FOT (Resmon Pro; MGC Diagnostics, USA) measurement at $8 \mathrm{~Hz}$ was performed with patient's cheeks supported by a technician, according to current guidelines [3]. Respiratory system resistance at $8 \mathrm{~Hz}\left(R_{\mathrm{rs}_{8}}\right)$ was expressed as age-specific height-adjusted reference values (Z-scores) using two different reference equations for 3-12-year-olds [9] and for 13-17-year-olds [10]. Then, baseline spirometry (EasyOne Pro Lab; NDD, Switzerland) was obtained [3], and forced vital capacity (FVC), forced expiratory volume in $1 \mathrm{~s}$ $\left(\mathrm{FEV}_{1}\right), \mathrm{FEV}_{1} / \mathrm{FVC}$ ratio and forced expiratory flow at $25-75 \% \mathrm{FVC}\left(\mathrm{FEF}_{25-75 \%}\right)$ were expressed as multiethnic reference values (Z-scores) [11]. 15 min after salbutamol (400 $\mu \mathrm{g})$ administration, the children were studied repeatedly with FOT and spirometry. Relative increases in $\mathrm{FEV}_{1} \geqslant 12 \%$ from baseline [12] or relative decreases in $R_{\mathrm{rs}_{8}} \leqslant-32 \%$ from baseline defined abnormal BDR [9]. Clinical data on age, sex, ethnicity and use of asthma medication prior the testing were available. Statistical analyses were performed with SPSS (version 26; IBM, USA). The results are expressed as means and standard deviations for continuous, and numbers and frequencies for categorised variables. ANOVA was used in the analysis of continuous, and Fisher's exact or Chi-squared tests in the analysis of categorised variables, as appropriate. Bivariate correlations (R) were reported with Pearson coefficients for normally distributed and with Spearman coefficients for non-normally distributed data.

@ERSpublications

Evaluation of airway obstruction with forced oscillation technique can be an adjunct to spirometry or even used as a primary method in those children unable to perform spirometry https://bit.ly/34rE6x2

Cite this article as: Lauhkonen E, Kaltsakas G, Sivagnanasithiyar S, et al. Comparison of forced oscillation technique and spirometry in paediatric asthma. ERJ Open Res 2021; 7: 00202-2020 [https://doi.org/10.1183/23120541.00202-2020]. 
All data were extracted retrospectively from de-identified clinical physiology reports. Ethical approval and data protection were provided by the Evelina London Children's Hospital local directorate review board (Guy's and St Thomas' NHS Foundation Trust, registration number 8901).

72 patients were measured during uninterrupted maintenance medication for asthma. Mean \pm SD age was $10.9 \pm 3.6$ years with range from 3.8 to 17.7 years. All 72 children were able to perform baseline FOT measurement. Six children ( $7.9 \pm 5.0$ years) were not able to produce repeatable spirometry, resulting in 66 (91.6\%) measurements with both baseline tests. 18 children were unable to proceed to post-bronchodilator measurements due to clinical reasons (poor baseline performance, lack of time or non-cooperation). These children were on average younger $(8.8 \pm 3.7$ years) compared to the $54(75 \%)$ children who were able to perform both baseline and post-bronchodilator tests $(11.6 \pm 3.3$ years, $\mathrm{p}=0.003)$. In these 54 cases $(51.9 \%$ male), reported ethnicities were $41 \%$ black, $46 \%$ Caucasian and $13 \%$ Asian; measured height $146 \pm 17.4 \mathrm{~cm}$; and weight $43 \pm 18.0 \mathrm{~kg} .13$ (24.1\%) reported use of bronchodilator within the last $12 \mathrm{~h}$ before BDR testing.

In 54 children with both lung function tests available, baseline spirometric indices were abnormal $(\leqslant-1.65$ Z-scores) for $\mathrm{FEV}_{1}$ in 21 (38.9\%), FVC in six (11.1\%), $\mathrm{FEV}_{1} / \mathrm{FVC}$ in 26 (48.1\%) and $\mathrm{FEF}_{25-75 \%}$ in 21 (38.9\%) cases. After bronchodilation, abnormal $\mathrm{FEV}_{1}$ was found in nine (16.7\%), FVC in five (9.3\%), $\mathrm{FEV}_{1} / \mathrm{FVC}$ in nine $(16.7 \%)$ and $\mathrm{FEF}_{25-75 \%}$ in 11 (20.4\%) cases. Bronchodilator administration increased $\mathrm{FEV}_{1}$ on average from $-1.19 \pm 1.44$ to $-0.40 \pm 1.21 \mathrm{Z}$-scores, FVC from $-0.33 \pm 1.14$ to $-0.01 \pm 1.07 \mathrm{Z}$-scores, $\mathrm{FEV}_{1} / \mathrm{FVC}$ from $-1.64 \pm 1.71$ to $-0.71 \pm 1.24 \mathrm{Z}$-scores and $\mathrm{FEF}_{25-75 \%}$ from $-1.45 \pm 1.48$ to $-0.47 \pm 1.53$ Z-scores. In FOT, $R_{\mathrm{rs}_{8}}$ was abnormal ( $\geqslant+1.65 \mathrm{Z}$-scores) at baseline in $20(37.0 \%)$ cases and after

a)
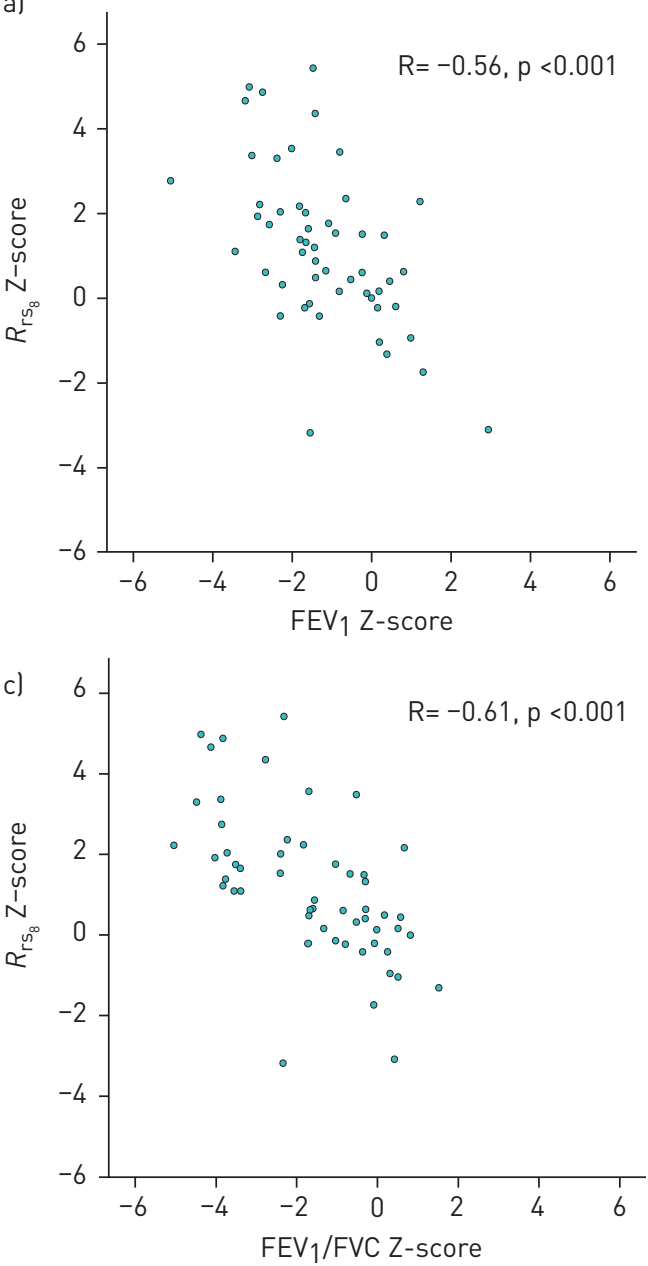

b)

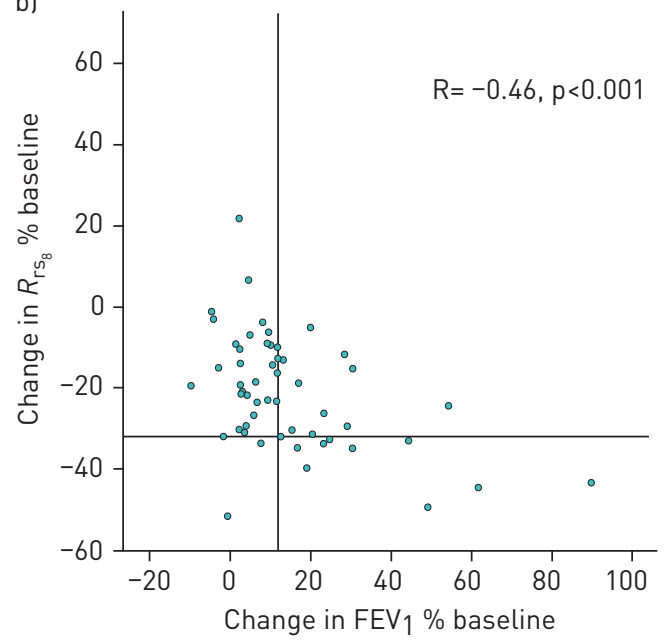

d)

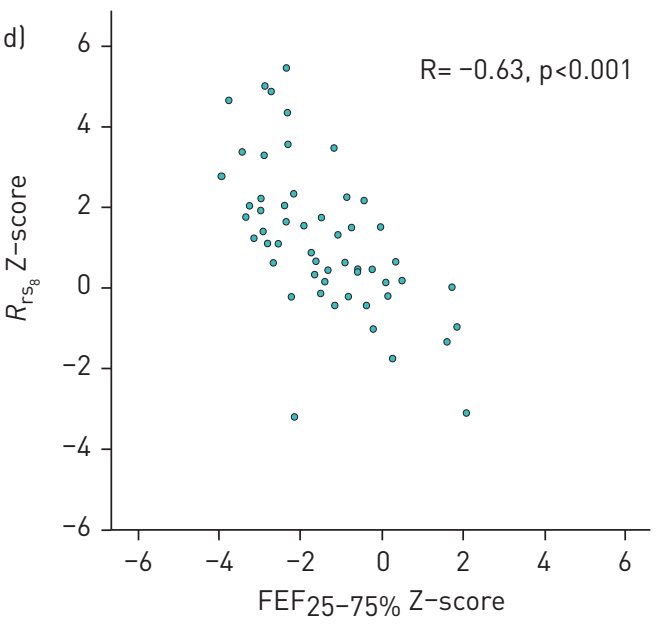

FIGURE 1 a) Bivariate correlation of baseline resistance of the respiratory system at $8 \mathrm{~Hz}\left(R_{\mathrm{rs}_{8}}\right)$ with forced expiratory volume in $\left.1 \mathrm{~s}\left(\mathrm{FEV}_{1}\right), \mathrm{b}\right)$ change in $R_{\mathrm{rs}_{8}}$ from baseline (cut-off $-32 \%$ ) and change in $\mathrm{FEV}_{1}$ from baseline (cut-off $+12 \%$ ), c) $R_{\mathrm{rs}_{8}}$ and $\mathrm{FEV}_{1} /$ forced vital capacity (FVC) and d) $R_{\mathrm{rs}_{8}}$ and forced expiratory flow at $25-75 \% \mathrm{FVC}\left(\mathrm{FEF}_{25-75 \%}\right)$ in 54 children with moderate to severe asthma at a mean age of 11.6 years. 
bronchodilation in five $(9.3 \%)$ cases. $R_{\mathrm{rs}_{8}}$ decreased on average from $1.21 \pm 1.85$ to $-0.73 \pm 1.87 \mathrm{Z}$-scores, respectively.

Statistically significant baseline FOT and spirometry bivariate correlations are presented in figure 1 . Baseline $R_{\mathrm{rs}_{8}}$ was significantly related with $\mathrm{FEV}_{1}(\mathrm{R}=-0.56, \mathrm{p}<0.001), \mathrm{FEV}_{1} / \mathrm{FVC}(\mathrm{R}=-0.61, \mathrm{p}<0.001)$ and $\mathrm{FEF}_{25-75 \%}(\mathrm{R}=-0.63, \mathrm{p}<0.001)$ but not with FVC. Post-bronchodilator $R_{\mathrm{rs}_{8}}$ was related with $\mathrm{FEV}_{1}(\mathrm{R}=-0.38, \mathrm{p}=0.005), \mathrm{FEV}_{1} / \mathrm{FVC}(\mathrm{R}=-0.35, \mathrm{p}=0.01)$ and $\mathrm{FEF}_{25-75 \%}(\mathrm{R}=-0.36, \mathrm{p}=0.008)$ but not with FVC. In BDR comparisons, decrease in $R_{\mathrm{rs}_{8}}$ was related with increase in $\mathrm{FEV}_{1}(\mathrm{R}=-0.46, \mathrm{p}<0.001)$ (figure 1).

There were $11(20.4 \%)$ children positive for BDR by FOT and 20 (37.0\%) positive for BDR by spirometry. BDR tests were in concordance in $76 \%$ (41 versus 13 out of $54, \mathrm{p}<0.001$ ). Two cases $(3.7 \%)$ were negative by spirometry but positive by FOT and $11(20.4 \%)$ positive by spirometry but negative by FOT. There were no significant differences in age, sex, ethnicity, height, weight, body mass index or use of any bronchodilator before the BDR between cases with test agreement and disagreement (data not shown).

There were three main findings when evaluating the relationship between FOT and spirometry in asthmatic children. Firstly, baseline lung function tests showed moderate correlations between $R_{\mathrm{rs}_{8}}$ and $\mathrm{FEV}_{1}, \mathrm{FEV}_{1} / \mathrm{FVC}$ and $\mathrm{FEF}_{25-75 \%}$ but not with FVC. Secondly, there was a fair consistency between BDR defined by relative change in $R_{\mathrm{rs}_{8}}$ and change in $\mathrm{FEV}_{1}$ from baseline. Thirdly, all children were able to perform FOT whereas the younger children were not able to perform spirometry.

The linear relationship between FOT and spirometry was strongest in baseline indices describing peripheral obstruction, i.e. $\mathrm{FEV}_{1} / \mathrm{FVC}$ and $\mathrm{FEF}_{25-75 \%}$. This reflects our study population demonstrating significant reversible obstruction. Similar magnitudes of correlation $(-0.51--0.71)$ have been described between baseline $\mathrm{FEV}_{1}$ and $R_{\mathrm{rs}_{5}}$ using impulse oscillometry $[13,14]$ but literature comparing FOT and spirometry in children is scarce. For BDR, a negative correlation of -0.46 was in line with previously reported relationship between $R_{\mathrm{rs}_{8}}$ and $\mathrm{FEV}_{1}$ [15].

There was a moderate agreement with BDR comparisons between FOT and spirometry, with 13 outliers having either a pathological response in $R_{\mathrm{rs}_{8}}$ or $\mathrm{FEV}_{1}$, but not both. No clear demographic factor was found to be associated with test disagreement. BDR by spirometry seemed to pick up more cases, and discrepancies in BDR between two methods may be related to technical and physiological factors. Bronchodilation changes in oscillometric indices are mathematically more dependent from baseline than spirometric indices. For example, when airway obstruction is present, FOT baseline $R_{\mathrm{rs}_{8}}$ is higher and the decrease due to bronchodilation is relatively smaller in percentage, whereas $\mathrm{FEV}_{1}$ shows more marked improvement in relation to baseline. However, oscillometry is thought to be more sensitive to peripheral airway obstruction than spirometry, and previously baseline measurements rather than BDR with impulse oscillometry were more effective in distinguishing uncontrolled asthma status in children [16]. As a limitation to more specific FOT analysis, reactance data were not available in this study.

We aimed to look at clinical performance and consistency of FOT and spirometry findings in children followed up at a tertiary level asthma clinic. Both baseline tests were available from $92 \%$ of children and $75 \%$ of children had both tests accepted after bronchodilation. The time to obtain two consequent measurements was limited and performance at baseline may have been affected if testing was continued further. These data were not fully recorded and thus direct feasibility comparisons were not available.

In conclusion, FOT showed moderate correlation with spirometry indices and was accessible to children with moderate to severe asthma. The findings support the use of FOT in adjunct with spirometry and even as a primary method in younger asthmatics unable to perform spirometry.

Eero Lauhkonen $\odot^{1}$, Georgios Kaltsakas $\odot^{2}$, Sindhu Sivagnanasithiyar $\odot^{1}$ and Richard Iles $\odot^{1}$

${ }^{1}$ Evelina London Children's Hospital, Guy's and St Thomas' NHS Hospital Trust, London, UK. ${ }^{2}$ Lane Fox Clinical Respiratory Physiology Research Centre, Centre for Human and Applied Physiological Science, School of Basic and Biomedical Science, King's College, London, UK.

Correspondence: Eero Lauhkonen, Lane Fox Respiratory Service, St Thomas' Hospital, Westminster Bridge Road, London SE1 7EH, UK. E-mail: eero.lauhkonen@fimnet.fi

Received: 20 April 2020 | Accepted: 25 Sept 2020

Author contributions: E. Lauhkonen performed the analysis and wrote the manuscript; G. Kaltsakas and R. Iles designed the study, and participated in analysis and writing of the manuscript; S. Sivagnanasithiyar performed the patient testing and participated in writing of the manuscript. All authors have approved the final version of this manuscript. 
Conflict of interest: None declared.

Support statement: E. Lauhkonen acknowledges post-doctoral grants from Paediatric Research Foundation Finland and Tampere Tuberculosis Foundation.

\section{References}

1 Global Initiative for Asthma. Global Strategy for Asthma Management and Prevention, 2019. Available from: www.ginasthma.org.

2 Turner SW, Craig LC, Harbour PJ, et al. Spirometry in 5-year-olds - validation of current guidelines and the relation with asthma. Pediatr Pulmonol 2007; 42: 1144-1151.

3 Beydon N, Davis SD, Lombardi E, et al. An official American Thoracic Society/European Respiratory Society statement: pulmonary function testing in preschool children. Am J Respir Crit Care Med 2007; 175: 1304-1345.

4 Dubois AB, Brody AW, Lewis DH, et al. Oscillation mechanics of lungs and chest in man. J Appl Physiol 1956; 8 : 587-594.

5 King GG, Bates J, Berger KI, et al. Technical standards for respiratory oscillometry. Eur Respir J 2020; 55: 1900753

6 Hellinckx J, De Boeck K, Bande-Knops J, et al. Bronchodilator response in 3-6.5 years old healthy and stable asthmatic children. Eur Respir J 1998; 12: 438-443.

7 Moeller A, Carlsen KH, Sly PD, et al. Monitoring asthma in childhood: lung function, bronchial responsiveness and inflammation. Eur Respir Rev 2015; 24: 204-215.

8 Shi Y, Aledia AS, Galant SP, et al. Peripheral airway impairment measured by oscillometry predicts loss of asthma control in children. J Allergy Clin Immunol 2013; 131: 718-723.

9 Calogero C, Simpson SJ, Lombardi E, et al. Respiratory impedance and bronchodilator responsiveness in healthy children aged 2-13 years. Pediatr Pulmonol 2013; 48: 707-715.

10 Ducharme FM, Davis GM, Ducharme GR. Pediatric reference values for respiratory resistance measured by forced oscillation. Chest 1998; 113: 1322-1328.

11 Quanjer PH, Stanojevic S, Cole TJ, et al. Multi-ethnic reference values for spirometry for the 3-95-yr age range: the Global Lung Function 2012 equations. Eur Respir J 2012; 40: 1324-1343.

12 Hopp RJ, Pasha MA. A literature review of the evidence that a $12 \%$ improvement in $\mathrm{FEV}_{1}$ is an appropriate cut-off for children. J Asthma 2016; 53: 413-418.

13 Vink GR, Arets HG, van der Laag J, et al. Impulse oscillometry: a measure for airway obstruction. Pediatr Pulmonol 2003; 35: 214-219.

14 Olaguibel JM, Alvarez-Puebla MJ, Anda M, et al. Comparative analysis of the bronchodilator response measured by impulse oscillometry (IOS), spirometry and body plethysmography in asthmatic children. J Investig Allergol Clin Immunol 2005; 15: 102-106.

15 Ducharme FM, Davis GM. Respiratory resistance in the emergency department: a reproducible and responsive measure of asthma severity. Chest 1998; 113: 1566-1572.

16 Shi Y, Aledia AS, Tatavoosian AV, et al. Relating small airways to asthma control by using impulse oscillometry in children. J Allergy Clin Immunol 2012; 129: 671-678. 